\title{
Concentración de inmunoglobulina $G$ en suero y calostro de cabras de acuerdo al número de crías de la camada
}

\author{
Auad, J.; Cooper, L.G.; Cerutti, J.; Lozano, A.; Marini, V.N. \\ Universidad Católica de Córdoba. Unidad Asociada a CONICET. Área de Ciencias Agrarias, Ingeniería, \\ Ciencias Biológicas y de la Salud. Av. Armada Argentina 3555, Córdoba, CP X5016DHK, \\ Tel.. 0351-4938000.E-mail: jorauad@hotmail.com
}

\begin{abstract}
Resumen
Auad, J.; Cooper, L.G.; Cerutti, J.; Lozano, A.; Marini, V.N.: Concentración de inmunoglobulina $G$ en suero y calostro de cabras de acuerdo al número de crías de la camada. Rev vet 27: 1, 11-13, 2016. En caprinos la placenta es sindesmocorial, lo que no permite el pasaje de inmunoglobulinas y los neonatos dependen de los anticuerpos calostrales. Por lo tanto el calostrado es un evento vital y, en nuestra región, no hay datos disponibles sobre la concentración de inmunoglobulina $\mathrm{G}(\mathrm{IgG})$ en suero y calostro de cabra con respecto al número de crías de la camada. El objetivo del trabajo fue establecer la concentración de IgG sérica en cabras y su relación con la concentración de $\operatorname{IgG}$ en calostro, así como determinar si el número de crías influye en la concentración maternal de IgG. Se estudiaron 16 cabras Anglo Nubian divididas en dos grupos según el tamaño de la camada. Grupo 1: cabras que parieron una cría, y grupo 2: cabras que parieron dos crías. La IgG se determinó por inmunodifusión radial simple. Se encontró una diferencia significativa entre la concentración de IgG sérica con la de calostro (p 0,0001). El tamaño de la camada no influyó en las concentraciones de IgG séricas ni calostrales (p 0,68$)$.
\end{abstract}

Palabras clave: cabritos, anticuerpos, suero, calostro, inmunodifusión radial simple.

\begin{abstract}
Auad, J.; Cooper, L.G.; Cerutti, J.; Lozano, A.; Marini, V.N.: Immunoglobulin G concentration in goat's serum and colostrum in relation to the litter size. Rev vet 27: 1, 11-13, 2016. The goat's placenta is syndesmochorial, which does not allow the passage of immunoglobulins, and the goat kids are dependent of colostrum antibodies. Therefore, the colostrum is a vital event and no data is available on the impact of the concentration of immunoglobulin $\mathrm{G}(\mathrm{IgG})$ serum and colostrum regarding efficiency in multiple calving. The objectives were to establish the serum concentration of IgG levels in goats and its relationship to the concentration of IgG in colostrum, and to determine if the litter size influences in the maternal concentration of IgG. Sixteen Anglo Nubian goats were included in the study. Goats were divided into two groups according to litter size. Group 1: goats that gave birth to a single kid, and group 2 goats that gave birth two kids. IgG were measured by single radial immunodiffusion. Significant difference between the serum concentration and the colostrum $\operatorname{IgG}$ concentration was found (p 0,0001). Litter size did not influence sera and colostrum IgG concentrations ( $\mathrm{p} 0,68)$.
\end{abstract}

Key words: goat kids, antibodies, serum, colostrum, radial immunodiffusion.

\section{INTRODUCCIÓN}

Cuando nace un mamífero, emerge de un útero estéril hacia un ambiente en el que se expone de inmediato a una multitud de microorganismos. Para sobrevivir, el neonato debe ser capaz de controlar la invasión microbiana en muy poco tiempo ${ }^{14}$. En mamíferos domés-

Recibido: 13 octubre 2015 - Aceptado: 20 enero 2016 ticos, el sistema inmune alcanza su desarrollo completo al momento del nacimiento, pero la capacidad de responder a los desafíos patogénicos en este período es inefectiva, debido a la falta de estimulación antigénica durante la gestación ${ }^{7}$.

En caprinos el tipo placentario es sindesmocorial, lo que no permite el pasaje de inmunoglobulinas y los neonatos dependen por completo de los anticuerpos que reciben por medio del calostro ${ }^{5}$. 
La transferencia preparto de inmunoglobulinas desde la circulación materna hacia las secreciones mamarias es un proceso activo, mediado por receptores específicos (FcRn) conocido como calostrogénesis. Tal mecanismo constituye una etapa diferenciada y de duración limitada que comienza varias semanas antes del parto y cesa de forma abrupta inmediatamente a posteriori del mismo. En calostro de rumiantes el isotipo predominante es la IgG y representa más del $85 \%$ de las inmunoglobulinas totales ${ }^{12}$.

El calostrado es un evento vital y en nuestra región no hay datos disponibles sobre el impacto de la concentración de IgG del calostro con respecto a la eficiencia en pariciones simples y múltiples. Por ende, los objetivos del trabajo fueron establecer la concentración sérica de IgG en el pre-parto de las cabras y su relación con la concentración de IgG del calostro, como así también determinar si el número de crías influye en la concentración maternal de IgG.

\section{MATERIAL Y MÉTODOS}

Población: se estudiaron 16 cabras Anglo Nubian alojadas en el Campus Experimental de la Facultad de Ciencias Agropecuarias de la Universidad Católica de Córdoba. Los animales estaban confinados en corrales diseñados para esta especie y fueron alimentados con una dieta equilibrada a su condición fisiológica. Se las dividió en dos lotes según el tamaño de la camada: grupo 1 (cabras que parieron una cría, constituido por 6 animales) y grupo 2 (cabras que parieron dos crías, conformado por 10 animales). El estudio se desarrolló cumpliendo con la guía de buenas prácticas en el manejo de animales ${ }^{4}$.

Muestras: se tomaron $5 \mathrm{ml}$ de sangre por punción de la vena yugular a las cabras una semana antes de la fecha probable de parto y una muestra de $20 \mathrm{ml}$ de calostro postparto de ambos medios de la glándula mamaria previo a la succión del cabrito. Las muestras de suero y calostro fueron almacenadas y mantenidas a $-80^{\circ} \mathrm{C}$ hasta su procesamiento.

Determinación de IgG: se realizó por inmunodifusión radial simple (IDRS), según técnica de Mancini ${ }^{8}$ empleando IgG de conejo anti cabra (Jackson ImmunoResearch Laboratories $\AA$, West Grove, PA, USA). Se realizó curva de calibración con un estándar de concentración conocida (Goat Gamma Globulin 1000 mg/dl Jackson ImmunoResearch Laboratories $\AA$, West Grove, PA, USA). Se tiñó la placa de inmunodifusión con azul brillante de Coomassie y la lectura de los halos se realizó mediante la toma de imágenes y la medición de los diámetros correspondientes a través del dispositivo periférico WebCam Philips SPC$530 \mathrm{Nc}{ }^{\circledR}, 1,3 \mathrm{Mp}$ zoom óptico x 3, empleando el software Philips CamSuite Capture ${ }^{\circledR}$ V.2.0.15.0. Las imágenes se procesaron mediante el software Carl Zeiss AxioVision ${ }^{\circledR R}$ Rel. 4.6. La concentración de IgG en mg/ dl de cada muestra se obtuvo por interpolación de la curva de calibración a través de planilla de cálculo.

Análisis estadístico: bajo un diseño observacional se realizó el análisis descriptivo de las variables. Para establecer asociación se utilizó un análisis de correlación. Para la comparación entre grupos se empleó prueba $t$ para muestras independientes o dependientes según correspondiere. Se consideró significativo un valor de $\mathrm{p}<0,05$.

\section{RESULTADOS}

El valor medio de $\operatorname{IgG}$ del total de animales en suero fue de $1749 \mathrm{mg} / \mathrm{dl}( \pm 73)$ y en calostro fue de $3720 \mathrm{mg} /$ $\mathrm{dl}( \pm 191)$. Se encontró una diferencia significativa $(\mathrm{p}$ $0,0001)$ entre la concentración de IgG sérica con la del calostro, presentando el calostro un 53\% más de esta inmunoglobulina con respecto al suero.

Los valores de IgG obtenidos en el grupo 1 (cabras que parieron una cría) fueron de $1762 \mathrm{mg} / \mathrm{dl}( \pm 51)$ en suero y de $3693 \mathrm{mg} / \mathrm{dl}( \pm 226)$ en calostro; mientras que en el grupo 2 (cabras que parieron dos crías) los valores hallados fueron de $1744 \mathrm{mg} / \mathrm{dl}( \pm 78)$ y de $3726 \mathrm{mg} / \mathrm{dl}$ $( \pm 185)$ respectivamente. Al comparar la concentración de IgG de acuerdo al número de crías, no se encontraron diferencias significativas entre los grupos con respecto a los valores en suero $(p 0,68)$ y en calostro (p 0,77$)$.

No se observó relación entre la concentración de IgG sérica con la concentración de $\mathrm{IgG}$ calostral en el total de las cabras estudiadas, ni cuando se las distribuyó de acuerdo al número de crías (Figura 1).

\section{DISCUSIÓN}

Las concentraciones de $\mathrm{IgG}$ en calostro y sus desvíos estándares aquí obtenidos fueron más bajos que

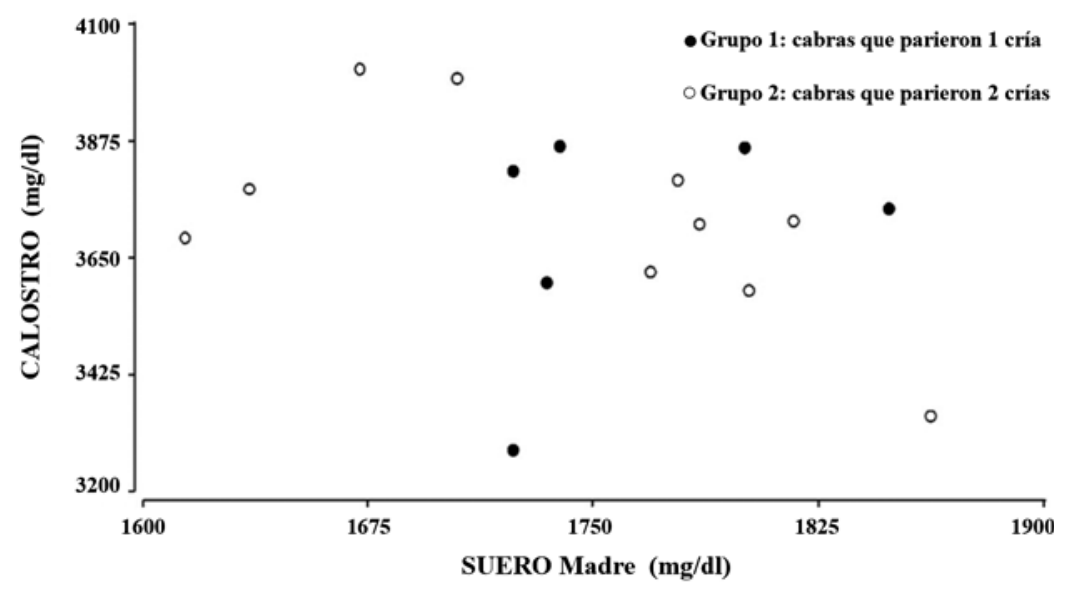

Figura 1. Relación entre concentración de IgG en suero y calostro de acuerdo al número de crías de la camada. 
los hallados en investigaciones previas ${ }^{13}$, en tanto que otros autores 3, 9,11 encontraron valores menores a los registrados en el presente trabajo. La técnica empleada para la determinación de $\mathrm{IgG}$ en los trabajos anteriormente citados fue ELISA y probablemente la diferencia en los valores hallados se asocie a la prueba utilizada. La IDRS, prueba de interacción secundaria, es considerada la técnica de referencia ${ }^{1,2,10}$.

Según el modelo planteado en nuestra investigación no se encontraron diferencias en la concentración de IgG en calostro de acuerdo al número de crías, circunstancia coincidente con reportes anteriores ${ }^{6}$.

Nuestros resultados muestran que no existe correlación entre las concentraciones de $\operatorname{IgG}$ en suero y calostro, teniendo un valor más elevado en la secreción mamaria. Se concluye que en cabras no existe relación entre el valor de IgG sérica y la concentración de esta inmunoglobulina en calostro. Asimismo, se confirma que el número de crías de la camada no influye en la concentración de IgG en calostro de la madre en el modelo planteado.

Agradecimientos. A la Méd. Vet. Soledad Aguilar, al Técn. Lab. Alfredo Mier, al Dr. Arnaldo Mangeaud, a los alumnos del Grupo Caprino y de la Cátedra de Clínica de Grandes Animales, así como a la Secretaría de Investigación de la Universidad Católica de Córdoba, por el apoyo recibido.

\section{REFERENCIAS}

1. Argüello A, Castro N, Capote J, Tyler JW, Hollowar NM. 2004. Effect of colostrum administration practices on serum IgG in goat kids. Lives Prod Sci 90: 235-239.

2. Argüello A, Castro N, Zamorano MJ, Castroalonso A, Capote J. 2004. Passive transfer of immunity in kid goats fed refrigerated and frozen goat colostrum and commercial sheep colostrum. Small Rum Res 54: 237-241.

3. Castro N, Capote J, Morales A, Rodriguez C, Argüello A. 2009. Effects of newborn characteristics and length of colostrum feeding period on passive immune transfer in goat kids. J Dairy Sci 92: 1616-1619.

4. Federation of Animal Sciences Societies (FASS). 2010. Guide for the care and use of agricultural animals in research and teaching, 3rd.ed., FASS Champaign, Ilinois (USA). On line: http://www.fass.org/docs/agguide3rd/ Ag_Guide_3rd_ed.pdf
5. Fernández A. 2006. Influence of colostrum treated by heat on immunity function in goat kids. Comp Immunol Microbiol Infect Dis 29: 353-364.

6. Lima A. 2008. Estudo da flutuação sérica de anticorpos maternos nos períodos pré e pós parto e transferência de imunidade passive em cabritos recém nascidos utilizando colostro bovino e caprino. Tesis Mestre em Agronomia, Universidade de São Paulo, Brasil.

7. Lunn DP, Horohov DW. 2005. El sistema inmune del caballo (Parte I- Capítulo 1). En: Medicina equina, $2^{\circ}$ ed., Inter-Médica, Buenos Aires, p. 1-32.

8. Mancini G, Vaerman C, Carbonara AO, Heremans JF. 1964. A single radial method for the immunological quantitation of proteins. Ann XI Colloquium on Protides of Biological Fluid, Amsterdam, p. 370.

9. Morales A, Moreno I, Sánchez D, Capote J, Juste MC, Castro N, Hernández Castellano LE, Agüello A. 2011. Sodium dodecyl sulfate reduces bacterial contamination in goat colostrums without negative effects on immune passive transfer or the health of goat kids. J Dairy Sci 94 : 410-415.

10. Pinn TL, Gagleardo LF, Purdy SR, Appleton JA, Stokol T. 2013. Comparison of three immunoglobulin G assays for the diagnosis of failure of passive transfer of immunity in neonatal alpacas. J Vet Diagn Invest 25: 91-98.

11. Ramos JJ, Loste A, Ferrer LM, Fernández A, Castro N, Ortín A, Verde MT, Argüello A, Figueras L. 2010. Effect of addition of soybean trypsin inhibitor to colostrum on immunological status in goat kids. J Anim Physiol Nutr 94: 93-98.

12. Roth JA. 2004. Inmunología neonatal bovina. En: Inmu-

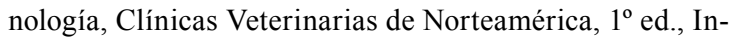
termédica, Buenos Aires, p. 1-15.

13. Rudovsky A, Locher L, Zeyner A, Sobiraj A, Witter T. 2008. Measurement of immunoglobulin concentration in goat colostrum. Small Rum Res 74: 265-269.

14. Tizard IR. 2009. Inmunidad en el feto y en el recién nacido. En: Inmunología Veterinaria, $8^{\circ}$ ed., Elsevier, Barcelona, p. 223-238. 